\title{
UPAYA PENINGKATAN HASIL BELAJAR MUATAN IPA MELALUI MODEL PEMBELAJARAN GROUP INVESTIGATION BERBANTUAN MEDIA VIDEO PADA SISWA KELAS 4 SD NEGERI KALIWUNGU 02 SEMESTER II
}

\author{
Erlin Damayanti', Wasitohadi², Theresia Sri Rahayu ${ }^{3}$ \\ 1Pendidikan Guru Sekolah Dasar, Universitas Kristen Satya Wacana, 292014108@student.uksw.edu \\ 2Pendidikan Guru Sekolah Dasar, Universitas Kristen Satya Wacana, wasitohadiuksw@gmail.com \\ 3Pendidikan Guru Sekolah Dasar, Universitas Kristen Satya Wacana, th.rahayu@gmail.com
}

\section{INFO ARTIKEL}

Riwayat Artikel:

Diterima: 27-03-2018

Disetujui: 10-04-2018

\section{Kata Kunci:}

Model pembelajaran group investigation

Hasil Belajar

IPA

\section{ABSTRAK}

Abstrak: Penelitian ini merupakan penelitian tindakan kelas (PTK). Penelitian ini bertujuan untuk meningkatkan hasil belajar muatan IPA dengan menggunakan model pembelajaran group investigation siswa kelas 4 SD Negeri Kaliwungu 02 Semester II. Penelitian ini dilaksanakan dalam dua siklus, dengan tiap siklus terdiri dari perencanaan, pelaksanaaan tindakan, observasi dan refleksi. Hasil penelitian adalah bahwa penerapan model group investigation dapat meningkatkan hasil belajar muatan ipa. Peningkatan hasil belajar muatan IPA dilihat dari asspek kognitif persentase ketuntasan untuk siklus I mencapai $82,5 \%$ dan meningkat pada siklus II menjadi $100 \%$.

\begin{abstract}
This research is a classroom action research (PTK). This study aims to improve the learning outcomes of IPA content by using the model of group investigation study of 4th grade students of SD Negeri Kaliwungu 02 Semester II. This study was conducted in two cycles, with each cycle consisting of planning, execution of action, observation and reflection. The result of this research is that the implementation of group investigation model can improve the learning result of ipa payload. The increase of learning outcomes of IPA payloads seen from the cognitive asset percentage of completeness for the first cycle reached $82.5 \%$ and increased in cycle // to $100 \%$
\end{abstract}

\section{A. LATAR BELAKANG}

Pendidikan sangat meningkatkan sumber daya manusia. Berdasarkan Undang-Undang Nomor 20 Tahun 2003 tentang Sistem Pendidikan Nasional, pendidikan harus mampu menjamin pemerataan kesempatan pendidikan dan peningkatan mutu pendidikan. Pemerataan kesempatan pendidikan diwujudkan dalam program wajib belajar 9 tahun. Peningkatan mutu pendidikan diarahkan untuk meningkatkan kualitas manusia Indonesia seutuhnya melalui olah batin, olah pikir, olah rasa, dan olah kinerja agar memiliki daya saing dalam menghadapi tantangan global. Berbagai upaya telah dilakukan oleh pemerintah untuk meningkatkan mutu pendidikan. Antara lain dengan melengkapi sarana dan prasarana sekolah, penyempurnaan kurikulum, meningkatkan kualitas tenaga pendidik, serta kualitas pembelajaran. Agar pelaksanaan pembelajaran berjalan dengan baik dan hasilnya dapat diandalkan maka perbaikan pengajaran diarahkan pada pengelolaan proses pembelajaran. Dalam hal ini bagaimana model pembelajaran yang akan diterapkan oleh guru dan strategi pembelajaran yang dikembangkan di sekolah menghasilkan luaran pendidikan sesuai dengan apa yang diharapkan.
Uno $(2011 ; 109)$ berpendapat bahwa kualitas lebih mengarah pada suatu keadaan yang baik. Sedangkan pembelajaran adalah upaya membelajarkan siswa. Jadi kualitas pembelajaran artinya bagaimana kegiatan pembelajaran yang dilakukan berjalan dengan baik serta menghasilkan yang baik pula.

Menurut Arends dalam Trianto (2012;84) model pembelajaran merupakan suatu perencanaan atau pola yang digunakan sebagai pedoman dalam merencanakan pembelajaran di kelas untuk membantu siswa mencapai tujuan pembelajaran.

Dalam pembelajaran IPA pada hakikatnya siswa belajar dari pengalamannya sendiri dan memperoleh pengetahuan. Kemudian memberi makna pada pengetahuan itu melalui proses belajar dengan mengalami dan menemukan sendiri secara berkelompok serta saling tukar pendapat, maka siswa menjadi senang dan tumbuhlah minat untuk belajar pada siswa. Berdasarkan hasil observasi, pembelajaran IPA di kelas 4 SD Negeri Kaliwungu 02 yang dilakukan oleh guru kurang menarik bagi siswa. Guru berpendapat bahwa tugas utamanya adalah memberikan pengetahuan pada siswa, sehingga dalam pembelajaran guru hanya menggunakan metode ceramah dan proses pembelajaran yang berlangsung di 
kelas hanya diarahkan pada kemampuan siswa untuk menghafal informasi tanpa dituntut untuk memahami informasi yang diperoleh. Dalam hal ini guru yang mendominasi kegiatan pembelajaran sedangkan siswanya pasif hanya duduk, diam dan mendengarkan penjelasan guru, sehingga siswa merasa jenuh dan bosan yang pada akhirnya tidak memperhatikan penjelasan guru serta siswa tidak dapat menjawab pertanyaan dari guru.

Wahyana dalam Trianto (2012) mengatakan bahwa IPA adalah suatu kumpulan pengetahuan yang tersusun secara sistematik, dan dalam penggunaannya secara umum terbatas pada gejala-gejala alam. Perkembangannya tidak hanya ditandai oleh adanya kumpulan fakta, tetapi oleh adanya metode ilmiah seperti observasi dan eksperimen serta menuntut sikap ilmiah seperti rasa ingin tahu, terbuka dan jujur.

Menurut Sutrisno (2007) IPA merupakan usaha manusia dalam memahami alam semesta melalui pengamatan yang tepat (correct) pada sasaran, serta menggunakan prosedur yang benar (true), dan dijelaskan dengan penalaran yang sahih (valid) sehingga dihasilkan kesimpulan yang betul (truth). IPA mengandung tiga hal: proses (usaha manusia memahami alam semesta), prosedur (pengamatan yang tepat dan prosedurnya benar), dan produk (kesimpulannya betul).

Menurut Samatowa dalam Sugiyanto (2013) IPA merupakan bagian dari ilmu pengetahuan atau sains yang berasal dari terjemahan kata-kata dalam bahasa inggris yaitu natural science. Natural yang dimaksudkan berhubungan dengan alam atau bersangkutan dengan alam, sedangkan science artinya ilmu pengetahuan. Jadi IPA dapat diartikan sebagai ilmu pengetahuan tentang alam. Ilmu yang mempelajari peristiwa-peristiwa yang terjadi di alam ini.

Sedangkan menurut Kardi dan Nur dalam Trianto (2012) IPA mempelajari tentang alam semesta, bendabenda yang ada dipermukaan bumi, di dalam perut bumi dan di luar angkasa, baik yang dapat diamati oleh indera maupun yang tidak dapat diamati oleh indera. Oleh karena itu IPA adalah ilmu tentang dunia zat, baik mahkluk hidup maupun benda mati yang diamati.

Dari pendapat para ahli dapat disimpulkan bahwa IPA merupakan ilmu yang berhubungan dengan gejala alam, pengetahuan diperoleh dari pengalaman belajar secara langsung melalui pengamatan serta pengembangan keterampilan proses dan sikap ilmiah untuk menumbuhkan kemampuan berfikir, bekerja dan bersikap ilmiah seperti rasa ingin tahu, terbuka dan jujur serta mengkomunikasikannya sebagai aspek penting kecakapan hidup melalui pemecahan masalahmasalah yang dapat diidentifikasikan. Perkembangannya tidak hanya ditandai oleh adanya kumpulan fakta, tetapi oleh adanya metode ilmiah seperi observasi dan eksperimen serta menuntut sikap ilmiah seperti rasa ingin tahu, terbuka dan jujur.

Proses pembelajaran yang berlangsung dengan metode ceramah kurang efektif terutama dalam pembelajaran IPA. Hal ini dapat dilihat setelah dilaksanakan ulangan tengah semester, hasil belajar siswa kurang memuaskan. Banyak siswa yang memperoleh nilai di bawah KKM yaitu 65. Dari 23 siswa hanya 10 siswa yang memperoleh nilai tuntas dengan persentase $43,5 \%$, sedangkan 13 siswa lainnya memperoleh nilai di bawah KKM dengan persentase $56,5 \%$.

Setelah mengetahui masalah yang dihadapi siswa dalam kegiatan pembelajaran tersebut, maka diperlukan model pembelajaran yang sesuai, menuntut siswa lebih aktif mulai dari tahap pertama sampai tahap akhir pembelajaran serta melatih siswa untuk menumbuhkan kemampuan berfikir mandiri, sehingga siswa dapat memahami materi secara optimal dan guru hanya sebagai fasilitator. Untuk mengatasi masalah tersebut, peneliti melakukan pembelajaran IPA dengan menggunakan model pembelajaran group investigation karena dapat meningkatkan hasil belajar siswa sesuai dengan pendapat dari Isjoni (2013). Dimana dalam model pembelajaran group investigation ini siswa diberi pilihan penuh untuk merencanakan apa yang ingin dipelajari bersama kelompok. Dengan demikian siswa akan tertarik dalam belajar IPA dan tidak merasa bosan selama proses pembelajaran berlangsung.

Langkah-langkah penerapan model pembelajaran group investigation menurut Sharan dalam Trianto (2009) yaitu sebagai berikut:

\section{Seleksi Topik}

Siswa memilih berbagai subtopik dalam suatu wilayah tertentu masalah umum yang biasanya digambarkan lebih dahulu oleh guru. Siswa selanjutnya diorganisasikan ke dalam kelompokkelompok kecil yang beranggotakan dua sampai enam siswa. Komposisi kelompoknya heterogen, baik dalam jenis kelamin, etnik, maupun kemampuan akademik.

\section{Merencanakan Kerjasama}

Siswa beserta guru merencanakan berbagai prosedur belajar khusus, tugas dan tujuan umum yang sesuai dengan berbagai subtopik yang dipilih dalam langkah satu.

\section{Implementasi}

Siswa melaksanakan rencana yang telah dirumuskan pada langkah dua. Pembelajaran melibatkan berbagai kegiatan dan keterampilan serta mendorong siswa untuk menggunakan berbagai sumber. Guru secara terus-menerus mengikuti kemajuan tiap kelompok dan memberi bantuan jika dibutuhkan. 


\section{Analisis dan sintesis}

Siswa menganalisis dan mensintesis berbagai informasi yang diperoleh pada langkah tiga, dan merencanakan agar dapat dirangkum dalam suatu penyajian yang menarik di depan kelas.

5. Penyajian hasil akhir

Semua kelompok menyajikan suatu presentasi yang menarik dari berbagai topik yang telah dipelajari agar semua siswa dalam kelas saling terlibat dan mencapai perspektif yang luas mengenai topik tersebut. Presentasi kelompok dikoordinasi oleh guru.

6. Evaluasi

Siswa beserta guru melakukan evaluasi mengenai kontribusi tiap kelompok terhadap pekerjaan kelas sebagai suatu keseluruhan. Evaluasi dapat mencakup tiap siswa secara individu atau kelompok, atau kedua-duanya.

Beberapa penelitian tentang peningkatan model pembelajaran Group Investigation terhadap hasil belajar diantaranya penelitian Vera Sandria (2012) Upaya Meningkatkan Hasil Belajar Siswa dengan Menggunakan Model Pembelajaran Kooperatif Tipe Group Investigation Pada Mata Pelajaran IPA di Kelas IV SD Negeri 147 Palembang, Sutanto (2012) Upaya Meningkatkan Hasil Belajar Siswa dengan Menggunakan Model Pembelajaran Kooperatif Tipe Group Investigation Pada Mata Pelajaran IPA di Kelas IV SD Negeri 147 Palembang.

\section{B. METODE PENELITIAN}

Jenis penelitian ini menggunakkan jenis Penelitian Tindakan Kelas (PTK) Kolaboratif yaitu peneliti bekerjasama dengan guru kelas. Penelitian ini dilakukan di SD Negeri Kaliwungu 02 yang terletak di Dusun Panggang, Desa Panggang, Kecamatan Kaliwungu, Kabupaten Semarang dan terletak ditepi jalan. Penelitian dilakukan Semester I, tahun ajaran 2017/2018 di SD Negeri Kaliwungu 02.

Penelitian ini dilakukan dalam dua siklus dengan tiap siklus dilaksanakan dalam tiga kali pertemuan yang terdiri dari dua pertemuan tatap muka dan satu pertemuan evaluasi. Siklus I terdiri dari empat tahap meliputi, tahap perencanaan tindakan, pelaksanaan tindakan, observasi tindakan serta refleksi. Hasil refleksi pada siklus I digunakan untuk perbaikan pada pembelajaran siklus II. Tahapan siklus II meliputi, tahap perencanaan tindakan, pelaksanaan tindakan, observasi tindakan serta refleksi.

Penelitian tindakan kelas siklus I dilaksanakan sebanyak 3 kali pertemuan yaitu 2 kali pertemuan tatap muka dan 1 kali pertemuan evaluasi. Penelitian ini dilaksanakan pada bulan Februari 2018 sampai dengan Maret 2018 pada semester genap tahun ajaran 2017/2018. Subjek penelitian ini adalah siswa kelas 4 SD Negeri Kaliwungu 02. Siswa kelas 4 SD Negeri
Kaliwungu 02 berjumlah 23 siswa terdiri dari 11 siswa laki-laki dan 12 siswa perempuan dengan karateristik siswa yang bervariasi.

Pada penelitian ini, peneliti menggunakan tes tertulis sebagai alat pengumpul data hasil belajar siswa tema 7 muatan IPA, dalam mengamati proses pembelajaran peneliti menggunakan lembar observasi. Pada uji validitas, instrumen soal tes siklus I dan II instrumen soal valid jika koefisien corrected item to total correlation minimal $\geq 0,30$. Pada siklus I uji reliabilitas instrumen soal setelah dikurangi item yang tidak valid jika diuji tingkat reliabilitasnya dengan Cronbach's Alpha sebesar o,877 dari 30 item yang diuji dan pada siklus II instrumen soal setelah dikurangi item yang tidak valid diuji tingkat reliabilitasnya dengan Cronbach's Alpha sebesar o,866 dari 30 item yang diuji.

Data yang diperoleh dari hasil pelaksanaan penelitian tindakan kelas adalah data kuantitatif. Penelitian ini menggunakan analisis kuantitatif dengan statistik deskriptif. Sedangkan data hasil belajar matematika dianalisis menggunakan teknik analisis deskriptif komparatif untuk membandingkan hasil belajar setelah tindakan siklus I dan siklus II.

\section{HASIL DAN PEMBAHASAN 1.Deskripsi Hasil Penelitian}

Hasil belajar IPA siswa kelas 4 SD Negeri Kaliwungu 02 sebelum diadakan penelitian, 13 siswa kelas 4 yang belum tuntas KKM yaitu 65 . Pembelajaranyang dilakukan oleh gurukurang menarik bagi siswa. Dalam pembelajaran guru hanya menggunakan metode ceramah dan proses pembelajaran yang berlangsung di kelas hanya diarahkan pada kemampuan siswa untuk menghafal informasi tanpa dituntut untuk memahami informasi yang diperoleh. Dalam hal ini guru yang mendominasi kegiatan pembelajaran sedangkan siswanya pasif hanya duduk, diam dan mendengarkan penjelasan guru, sehingga siswa merasa jenuh dan bosan yang pada akhirnya tidak memperhatikan penjelasan guru serta siswa tidak dapat menjawab pertanyaan dari guru. Hal ini juga menyebabkan hasil belajar siswa rendah dan banyak siswa tidak tuntas hasil belajar IPA yang sesui KKM. Ketuntasan hasil belajar IPA pra siklus dapat dilihat pada tabel 1 .

TABEL 1

KETUNTASAN HASIL BELAJAR IPA PRA SIKLUS

\begin{tabular}{|l|l|c|c|}
\hline No & \multicolumn{1}{|c|}{ Ketuntasan } & Frekuensi & Persentase \\
\hline 1 & Tuntas & 10 & $43,5 \%$ \\
\hline 2 & Tidak tuntas & 13 & $56,5 \%$ \\
\hline Jumlah & 23 & $100 \%$ \\
\hline Nilai maksimum & \multicolumn{2}{|c|}{72} \\
\hline Nilai minimum & \multicolumn{2}{|c|}{60} \\
\hline Rata-rata & \multicolumn{2}{|c|}{65} \\
\hline KKM & \multicolumn{2}{|c|}{65} \\
\hline
\end{tabular}


Berdasarkan tabel 1 diketahui dari jumlah keseluruhan 23 siswa, hanya 10 siswa yang memperoleh nilai tuntas (43,5\%), sedangkan13 siswa belum tuntas $(56,5 \%)$. Nilai tertinggi yang diperoleh siswa adalah 72 dan nilai terendah 60 dengan nilai rata-rata yaitu 65 .

\section{Diskripsi Siklus I}

Pembelajaran siklus I di kelas 4 SD Negeri Kaliwungu 02 terdiri dari 3 kali pertemuan. Pada tahap perencanaan ini menyusunan RPP untuk pertemuan 1 dan pertemuan 2 dengan materi macam-macam gaya, antara lain gaya otot, gaya listrik, gaya magnet, gaya gravitasi, gaya gesekan serta manfaat gaya dalam kehidupan sehari-sehari, selanjutnya dilanjutkan pertemuan 3 yaitu memberikan soal evaluasi yang berjumlah 20 soal berbentuk pilihan ganda untuk mengetahui hasil belajar siswa setelah menerapkan model pembelajaran group investigation. Membuat lembar observasi untuk mengetahui kegiatan mengajar guru dan belajar siswa selama proses pembelajaran.

Hasil belajar IPA pada akhir siklus I sebagaitingkat pemahaman siswa tentang macammacam gaya, antara lain gaya otot, gaya listrik, gaya magnet, gaya gravitasi, gaya gesekan serta manfaat gaya dalam kehidupan sehari-sehari masih kurang. Ketuntasan hasil belajar IPA siklus I dapat dilihat pada tabel 2.

TABEL 2

KETUNTASAN HASIL BELAJAR IPA SIKLUS I

\begin{tabular}{|l|l|c|c|}
\hline No & Ketuntasan & Frekuensi & Persentase (\%) \\
\hline $\mathbf{1}$ & Tuntas & 19 & $82,5 \%$ \\
\hline $\mathbf{2}$ & Tidak tuntas & 4 & $17,5 \%$ \\
\hline Jumlah & 23 & $100 \%$ \\
\hline Nilai maksimum & \multicolumn{2}{|c|}{80} \\
\hline Nilai minimum & \multicolumn{2}{|c|}{55} \\
\hline Rata-rata & \multicolumn{2}{|c|}{67} \\
\hline KKM & \multicolumn{2}{|c|}{65} \\
\hline
\end{tabular}

Berdasarkan tabel 2 menunjukkan sebanyak 19 siswa sudah tuntas dan sebanyak 4 siswa belum tuntas. Nilai tertinggi yang diperoleh siswa pada siklus I adalah 80 dan nilai terendahnya 55 dengan nilai rata-rata 67.

\section{Deskripsi Siklus II}

Hasil belajar IPA pada akhir siklus II sebagai tingkat pemahaman siswa tentang macam-macam gaya, antara lain gaya otot, gaya listrik, gaya magnet, gaya gravitasi, gaya gesekan serta manfaat gaya dalam kehidupan sehari-sehari sudah tuntas secara klasikal. Ketuntasan hasil belajar IPA siklus II dapat dilihat pada tabel 3 .
TABEL 3

KETUNTASAN HASIL BELAJAR IPA SIKLUS II

\begin{tabular}{|l|l|c|c|}
\hline No & Ketuntasan & Frekuensi & Persentase \\
\hline 1 & Tuntas & 23 & $100 \%$ \\
\hline 2 & Tidak tuntas & 0 & $0 \%$ \\
\hline Jumlah & 23 & $100 \%$ \\
\hline Nilai maksimum & \multicolumn{2}{|c|}{100} \\
\hline Nilai minimum & \multicolumn{2}{|c|}{65} \\
\hline Rata-rata & \multicolumn{2}{|c|}{76} \\
\hline KKM & \multicolumn{2}{|c|}{65} \\
\hline
\end{tabular}

Berdasarkan tabel 3 menunjukkan sebanyak 23 siswa sudah tuntas. Nilai tertinggi yang diperoleh siswa adalah 100, dan nilai terendah 65 dengan nilai rata-rata 76 . Ketuntasan hasil belajar siswa secara klasikal pada siklus II sudah mencapai $100 \%$ dan nilai rata-rata kelas lebih besar dari KKM yaitu 65 .

\section{Analisa Komparatif}

\section{i. Hasil Belajar}

Berdasarkanh asil penelitian dapat diketahui adanya peningkatan hasil belajar IPA siswa Kelas SD Negeri Kaliwungu o2 melalui penerapan model pembelajaran group investigation. Perbandingan ketuntasan hasil belajar IPA pada prasiklus, siklus I, dan siklus II dapat dilihat pada tabel 4.

TABEL 4

PERBANDINGAN KETUNTANSAN HASIL BELAJAR IPA PADA PRA SIKLUS, SIKLUS I,DAN SIKLUS II

\begin{tabular}{|c|c|c|c|c|c|c|c|}
\hline \multirow[t]{2}{*}{ No } & \multirow{2}{*}{$\begin{array}{c}\text { Ket } \\
\text { unt } \\
\text { asa } \\
\text { n }\end{array}$} & \multicolumn{2}{|c|}{ Pra siklus } & \multicolumn{2}{|c|}{ Siklus I } & \multicolumn{2}{|c|}{ Siklus II } \\
\hline & & $\begin{array}{c}\text { Fre } \\
\text { kue } \\
\text { nsi }\end{array}$ & $\begin{array}{c}\text { Persen } \\
\text { tase }\end{array}$ & $\begin{array}{l}\text { Fre } \\
\text { kue } \\
\text { nsi }\end{array}$ & $\begin{array}{l}\text { Perse } \\
\text { ntase }\end{array}$ & $\begin{array}{l}\text { Fre } \\
\text { kue } \\
\text { nsi }\end{array}$ & $\begin{array}{c}\text { Pers } \\
\text { enta } \\
\text { se }\end{array}$ \\
\hline 1 & $\begin{array}{l}\text { Tun } \\
\text { tas }\end{array}$ & 10 & $43,5 \%$ & 19 & $\begin{array}{c}82,5 \\
\%\end{array}$ & 23 & $\begin{array}{c}100 \\
\%\end{array}$ \\
\hline 2 & $\begin{array}{l}\text { Tid } \\
\text { ak } \\
\text { tunt } \\
\text { as }\end{array}$ & 13 & $56,5 \%$ & 4 & $17,5 \%$ & 0 & $0 \%$ \\
\hline \multicolumn{2}{|c|}{ Jumlah } & 23 & $100 \%$ & 23 & $100 \%$ & 23 & $\begin{array}{c}100 \\
\%\end{array}$ \\
\hline \multicolumn{2}{|c|}{$\begin{array}{l}\text { Nilai } \\
\text { maksimum }\end{array}$} & \multicolumn{2}{|c|}{72} & \multicolumn{2}{|c|}{80} & \multicolumn{2}{|c|}{100} \\
\hline \multicolumn{2}{|c|}{$\begin{array}{l}\text { Nilai } \\
\text { minimum }\end{array}$} & \multicolumn{2}{|c|}{60} & \multicolumn{2}{|c|}{55} & \multicolumn{2}{|c|}{65} \\
\hline \multicolumn{2}{|c|}{ Rata-rata } & \multicolumn{2}{|r|}{65} & \multicolumn{2}{|c|}{67} & \multicolumn{2}{|c|}{76} \\
\hline \multicolumn{2}{|c|}{ KKM } & \multicolumn{2}{|r|}{65} & \multicolumn{2}{|c|}{65} & \multicolumn{2}{|c|}{65} \\
\hline
\end{tabular}

Berdasarkan tabel 4 dapat dilihat adanya peningkatan hasil belajar siswa. Pada pra siklus ada 10 siswa yang tuntas dan 13 siswa belum tuntas. Nilai tertinggi yang berhasil diperoleh siswa sebelum dilakukan tindakan adalah 72 sedangkan nilai terendah 60 dengan ratarata 65. Setelah diadakan tindakan pembelajaran dengan menggunakan model group investigation, pada siklus I ada 19 siswa yang tuntasdan 4 siswa belum tuntas. Nilai tertinggi yang diperoleh siswa pada siklus I adalah 80, dan nilai terendah 55 dengan 
rata-rata 67. Sedangkan siklus II ada 23 siswa yang tuntas. Nilai tertinggi yang diperoleh siswa pada siklus II adalah 100, dan nilai terendah 65 dengan rata-rata 76 . Ini membuktikan bahwa proses belajar mengajar menggunakan model pembelajaran group investigation dapat meningkatkan hasil siswa sesuai dengan pendapat dari Isjoni (2013).

\section{Pembahasan}

Rendahnya hasil belajar muatan IPA diketahui berdasarkan hasil belajar muatan IPA di kelas 4 SD Negeri Kaliwungu 02 yang dibuktikan berdasarkan tingkat ketuntasan hasil belajar prasiklus, bahwa siswa yang tuntas atau telah mencapai KKM (65) hanya 10 siswa atau $43,5 \%$ dari jumlah keseluruhan siswa, sedangkan yang belum mencapai KKM ada 13 siswa atau 56,5\% dari jumlah keseluruhan siswa. Berdasarkan kondisi yang demikian maka peneliti merasa diperlukan adanya tindakan perbaikan pembelajaran untuk meningkatkan hasil belajar muatan IPA siswa kelas 4 SD Negeri Kaliwungu 02 dengan menerapkan model pembelajaran group investigation.

Setelah pembelajaran muatan IPA dengan menerapkan model pembelajaran group investigation dilaksanakan secara keseluruhan pada siklus I dan siklus II. Siswa menjadi lebih berpartisipasi aktif dalam proses pembelajaran. Pada Siklus I diperoleh niai rata-rata 67 dengan pencapaian ketuntasan mencapai 82,5\%. Pada siklus II diperoleh nilai rata-rata kelas meningkat menjadi 76 dengan pencapaian ketuntasan belajar mencapai $100 \%$ tuntas.

Model group investigation membuat siswa dapat belajar dalam suasana yang menyenangkan, dan merasa memiliki kemampuan untuk menemukan sesuatu yang baru, mengurangi perasaan takut dan tegang yang dirasakan oleh siswa saat mengikuti proses pembelajaran. Pembelajaran dengan menggunakan model pembelajaran group investigation juga menjadikan siswa dapat berinteraksi dan bekerja sama dengan baik dengan siswa yang lain. Selain itu guru juga menanamkan pada peserta didik pentingnya pengamatan empiris dalam menguji suatu pernyataan ilmiah (hipotesis). Hipotesis ini dapat berasal dari pengamatan terhadap kejadian sehari-hari yang memerlukan pembuktian secara ilmiah, latihan berpikir kuantitatif yang mendukung kegiatan belajar muatan IPA, yaitu sebagai penerapan muatan IPA pada masalahmasalah nyata yang berkaitan dengan peristiwa alam, hal ini dimaksudkan untuk menambah semangat siswa dalam mengikuti pembelajaran.

Dengan pelaksanaan tindakan pembelajaran pada siklus I dan siklus II dengan menerapkan model pembelajaran group investigation siswa bisa merespon pertanyaan dari guru, siswa bisa mengenal masalah, siswa bisa memecahkan masalah, siswa bisa menyelidiki masalah sendiri, siswa bisa berfikir intuisi dan merumuskan hipotesis sendiri, siswa bisa mengembangkan bakat dan kecakapan individu, siswa bisa berfikir dan menggunakan kemampuan untuk menemukan hasil akhir sehingga siswa menjadi lebih aktif dan guru bisa melakukan inovasi dalam pembelajaran sehingga dapat meningkatkan hasil belajar muatan IPA. Berdasarkan uraian penelitian yang telah disajikan, maka penerapan model pembelajaran Group Investigation dalam pembelajaran muatan IPA pada siswa kelas 4 SD Negeri Kaliwungu 02 Semester II Tahun Pelajaran 2017/2018 terbukti bahwa penerapan model pembelajaran group investigation dapat meningkatkan hasil belajar siswa.

\section{SIMPULAN DAN SARAN}

Berdasarkan hasil penelitian tindakan kelas yang dilaksanakan dikelas 4 SD Negeri Kaliwungu 02 Semester II, maka dapat disimpulkan bahwa penggunaan model pembelajaran group investigation pada muatan IPA dapat meningkatkan hasil belajar siswa. Untuk KKM yang telah ditentukan sekolah adalah 65. Hasil belajar siswa saat pra siklus sebanyak 10 siswa $(43,5 \%)$ tuntas dengan nilai rata-rata 65 , pada siklus I meningkat menjadi 19 siswa $(82,5 \%)$ tuntas dengan nilai rata-rata 67 , dan pada siklus II meningkat menjadi 23 siswa (100\%) tuntas dengan nilai rata-rata 76.

Berdasarkan simpulan di atas, maka penulis memberikan saran sebagai berikut:

1. Bagi siswa: Bila mengikuti pembelajaran dengan model group investigation yang disarankan peneliti, siswa dihimbau untuk lebih aktif mengikuti pembelajaran, karena tahap-tahap model group investigation merangsang siswa menjadi tertarik dalam pembelajaran muatan IPA sehingga siswa mudah memahami materi dan hasil belajar meningkat.

2. Bagi guru: Guru dihimbau dalam pembelajaran hendaknya menggunakan model group investigation karena terbukti dalam penelitian ini dapat meningkatkan hasil belajar siswa pada pembelajaran muatan IPA.

3. Bagi sekolah: Kepala sekolah sebaiknya menyarankan guru supaya menggunakan model group investigation dalam pembelajaran dan mengadakan pelatihan atau seminar tentang model pembelajaran salah satunya yaitu model group investigation.

\section{UCAPAN TERIMA KASIH}

Dengan ini penulis mengucapkan terimakasih kepada Bapak Dr. Wasitohad, M.Pd Ibu Theresia Rahayu, M.Pd yang telah membimbing dan membantu sehingga penulis dapat menyelesaikan penelitian ini. 


\section{DAFTAR RUJUKAN}

[1] Isjoni. 2013. Pembelajaran Kooperatif Meningkatkan Kecerdasan Komunikasi Antar Peserta Didik. Yogyakarta: Pustaka Belajar.

[2] Subyantoro. 2014. PenelitianTindakanKelas. Semarang: Duta Publishing Indonesia.

[3] Sugiyanto. 2013. Upaya Peningkatan Hasil Belajar IPA Dengan Menggunakan Model Group Investigation Pada Siswa Kelas 4 SD Negeri o3 Karanganyar Kabupaten Grobogan Semester 2 TahunPelajaran 2012/2013.

[4] Sutanto. 2012. UpayaMeningkatanHasil Belajar IPA MelaluiModel Pembelajaran Group Investigation (GI) Pada Siswa Kelas V SD Negeri Gejayan Kecamatan Pakis Kabupaten MagelangTahun Pelajaran 2011/2012http://repository.library.uksw.edu/bitstrea m/handle/123456789/2661/T1 292010801 Judul.pdf? sequence $=1$.Diakses 14 Februari 2014.

[5] Sutrisno, Leo, dkk. 2007. Pengembangan Pembelajaran $I P A \quad S D$. Direktorat Jenderal Pendidikan Tinggi Departemen Pendidikan Nasional.

[6] Trianto. 2009. Mendesain Model Pembelajaran Inovatif-Progresif. Jakarta: Kencana Prenada Media Group.

[7] Trianto. 2012. Model PembelajaranTerpadu. Jakarta: BumiAksara.

[8] Uno, Hamzah B. . 2011. Model Pembelajaran Menciptakan Proses Belajar Mengajar yang Kreatif dan Efektif. Jakarta : PT Bumi Aksara.

[9] Vera Sandria. 2012. Upaya Meningkatkan Hasil Belajar Siswa dengan Menggunakan Model Pembelajaran KooperatifTipe Group Investigation Pada Mata Pelajaran IPA di Kelas IV SD Negeri 147 Palembanghttp://www.akademik.unsri.ac.id/paper4/ download/paper/TA56081013029.doc.

\section{PROFIL PENULIS UTAMA}

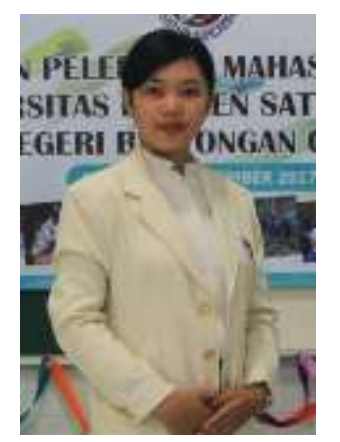

Penulis bernama lengkap "Erlin Damayanti". Lahir di Desa Kaliwungu Kecamatan Kaliwungu Kabupaten Semarang Provinsi Jawa Tengah pada tanggal 14 Juni 1996 dari pasangan Darwanto dan Haryanti. Penulis adalah anak kedua dari 2 bersaudara. Pendidikan sekolah dasar dimulai dari SDN Kaliwungu 02 Kecamatan Kaliwungu pada tahun 2002 - 2008. Setelah itu melanjutkan pendidikan sekolah menengah ke SMPN 1 Ampel pada tahun 2008 - 2011 dan terakhir di SMAN 2 Salatiga pada tahun $2011-2014$. Kemudian penulis melanjutkan studi ke perguruan tinggi di Program Studi Pendidikan Guru Sekolah Dasar FKIP UKSW pada tahun 2014. Kritik, saran, maupun hal-hal yang berkaitan dengan kelanjutan atau pengembangan dari hasil penelitian ini bisa dikirim ke email penulis di :

292014108@student.uksw.edu 